\title{
Effect of Transporting Saltstone Samples Prior to Set
}

M. M. Reigel

May 2013

Savannah River National Laboratory Savannah River Nuclear Solutions, LLC Aiken, SC 29808

Prepared for the U.S. Department of Energy under contract number DE-AC09-08SR22470. 
SRNL-STI-2013-00261

Revision 0

\section{DISCLAIMER}

This work was prepared under an agreement with and funded by the U.S. Government. Neither the U.S. Government or its employees, nor any of its contractors, subcontractors or their employees, makes any express or implied:

1. warranty or assumes any legal liability for the accuracy, completeness, or for the use or results of such use of any information, product, or process disclosed; or

2. representation that such use or results of such use would not infringe privately owned rights; or

3. endorsement or recommendation of any specifically identified commercial product, process, or service.

Any views and opinions of authors expressed in this work do not necessarily state or reflect those of the United States Government, or its contractors, or subcontractors.

\section{Printed in the United States of America}

Prepared for U.S. Department of Energy 
Keywords: Saltstone

Sampling

Retention: Permanent

\section{Effect of Transporting Saltstone Samples Prior to Set}

M. M. Reigel

May 2013

Savannah River National Laboratory Savannah River Nuclear Solutions, LLC Aiken, SC 29808

Prepared for the U.S. Department of Energy under contract number DE-AC09-08SR22470. 


\section{REVIEWS AND APPROVALS}

AUTHORS:

M. M. Reigel, Engineering Process Development

Date

TECHNICAL REVIEW:

C. A. Langton, Engineering Process Development

Date

APPROVAL:

E. N. Hoffman, Manager

Date

Engineering Process Development

S.L. Marra, Manager

Date

Environmental \& Chemical Process Technology Research Programs

S. P. Simner, SRR Grout SME

Date

K. H. Rosenberger, Manager

Date

SRR Closure and Disposal Assessment 


\section{EXECUTIVE SUMMARY}

The Saltstone Sampling and Analyses Plan provides a basis for the quantity (and configuration) of saltstone grout samples required for conducting a study directed towards correlation of the Performance Assessment (PA) related properties of field-emplaced samples and samples processed and cured in the laboratory. The testing described in the saltstone sampling and analyses plan will be addressed in phases. The initial testing (Phase I) includes collecting samples from the process room in the Saltstone Production Facility (SPF) and transporting them to Savannah River National Laboratory (SRNL) where they will cure under a temperature profile that mimics the temperature in the Saltstone Disposal Unit (SDU) and then be analyzed. SRNL has previously recommended that after the samples of fresh (uncured) saltstone are obtained from the SPF process room, they are allowed to set prior to transporting them to SRNL for curing. The concern was that if the samples are transported before they are set, the vibrations during transport may cause artificial delay of structure development which could result in preferential settling or segregation of the saltstone slurry. However, the results of this testing showed there was no clear distinction between the densities of the cylinder sections for any of the transportation scenarios tested ( 1 day, 1 hour, and 0 minutes set time prefer to transportation). The bottom section of each cylinder was the densest for each transportation scenario, which indicates some settling in all the samples. Triplicate hydraulic conductivity measurements on samples from each set of time and transportation scenarios indicated that those samples transported immediately after pouring had the highest hydraulic conductivity. Conversely, samples that were allowed to sit for an hour before being transported had the lowest hydraulic conductivity. However, the hydraulic conductivities of all three samples fell within an acceptable range. Based on the cured property analysis of the three samples, there is no clear conclusion about transporting the samples before they are set; however, experience with saltstone grout indicates the samples should sit and develop some structure before being transported to SRNL for curing. 


\section{TABLE OF CONTENTS}

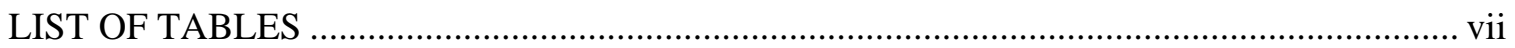

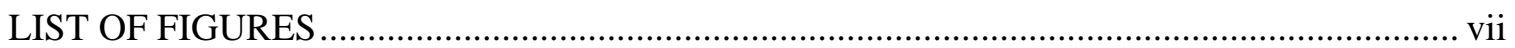

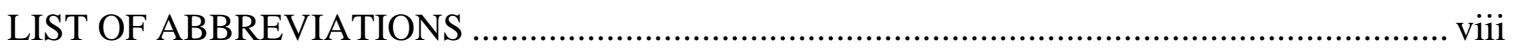

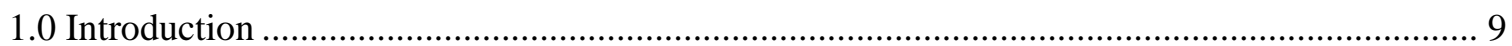

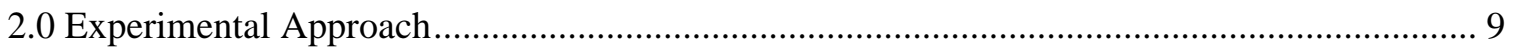

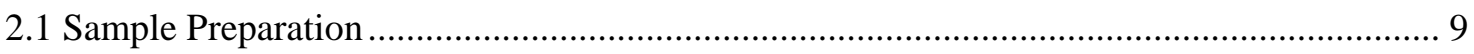

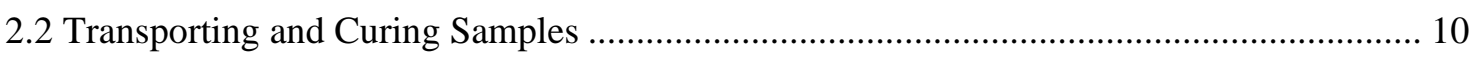

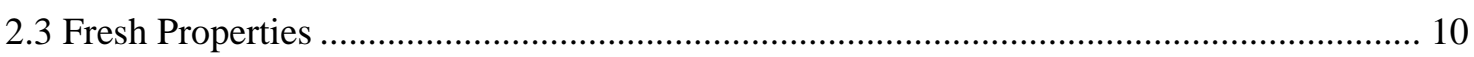

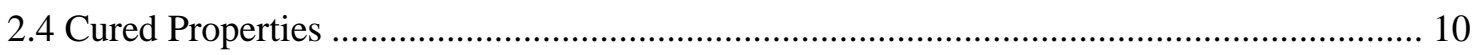

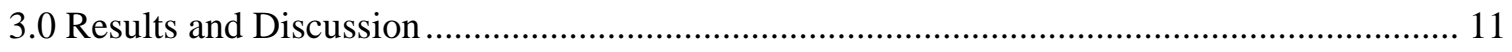

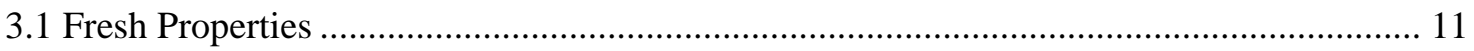

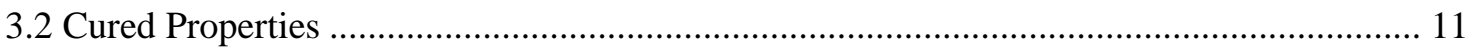

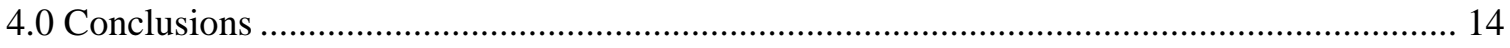

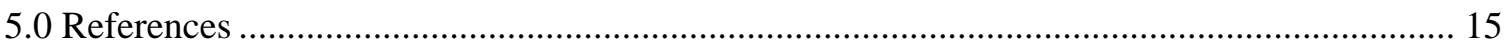




\section{LIST OF TABLES}

Table 2-1. Samples matrix for transportation study................................................................. 9

Table 3-1. Fresh properties of saltstone transportation samples............................................... 11

Table 3-2. Density $\left[\mathrm{g} / \mathrm{cm}^{3}\right]$ of saltstone transportation samples measured by pycnometry.......... 12

Table 3-3. Measured densities and pore volumes for saltstone transportation samples according

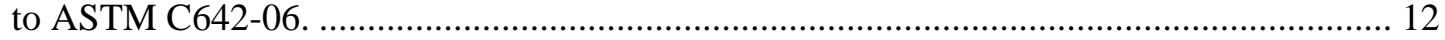

Table 3-4. Hydraulic Conductivities for saltstone transportation samples ................................... 13

\section{LIST OF FIGURES}

Figure 2-1. Sectioning of 2 x 4 inch samples for density measurements. ................................... 10

Figure 3-1. Measured densities for all samples by Pycnometry and ASTM C642-06................ 13

Figure 3-2. Hydraulic conductivity of saltstone transportation samples ..................................... 14 


\section{LIST OF ABBREVIATIONS}

$\begin{array}{ll}\text { ACTL } & \text { Aiken County Technology Laboratory } \\ \text { ASTM } & \text { American Society for Testing and Materials } \\ \text { PA } & \text { Performance Assessment } \\ \text { SDU } & \text { Saltstone Disposal Unit } \\ \text { SPF } & \text { Saltstone Production Facility } \\ \text { SRNL } & \text { Savannah River National Laboratory } \\ \text { SRR } & \text { Savannah River Remediation } \\ \text { TTQAP } & \text { Task Technical and Quality Assurance Plan } \\ \text { w/p } & \text { Water to premix }\end{array}$




\subsection{Introduction}

The Saltstone Sampling and Analyses Plan provides a basis for the quantity (and configuration) of saltstone grout samples required for conducting a study directed towards correlation of the Performance Assessment (PA) related properties of field-emplaced samples and samples processed and cured in the laboratory. ${ }^{1}$ The testing described in the sampling and analyses plan will be addressed in phases. The initial testing (Phase I) includes collecting samples from the process room in the Saltstone Production Facility (SPF) and transporting them to Savannah River National Laboratory (SRNL) where they will cure under a temperature profile that mimics the temperature in the Saltstone Disposal Unit (SDU) and then be analyzed. ${ }^{1}$ These samples included in Phase I are noted as "Sample Type C" in the sampling and analysis plan.

Savannah River Remediation (SRR) tasked SRNL with performing testing to assess the potential consolidation of grout associated with transportation from the SPF to SRNL. ${ }^{2}$ As stated in the Task Technical and Quality Assurance Plan (TTQAP), SRNL will determine if transporting the samples prior to set causes preferential settling or segregation of the saltstone slurry that adversely affect the cured properties of the saltstone samples. ${ }^{3}$ The variable affecting this study was set time prior to driving the samples across site. ${ }^{3}$

\subsection{Experimental Approach}

\subsection{Sample Preparation}

Three separate batches of simulated saltstone were mixed in the Aiken County Technology Laboratory (ACTL) grout laboratory and allowed to sit for various amounts of time before they were driven on site roads for approximately 15 miles to simulate the distance from the SPF to SRNL (Table 2-1). One hour was chosen as the approximate time from when samples were collected in the process room and loaded onto a truck. The samples for this study were prepared using the average CY2011 Tank 50 salt solution simulant ${ }^{4}$ and a premix blend of $45 \mathrm{wt} \%$ blast furnace slag, $45 \mathrm{wt} \%$ fly ash and $10 \mathrm{wt} \%$ cement. The salt solution and dry feeds were mixed in a 0.60 water to premix (w/p) ratio and no admixtures were used. The saltstone mixes were prepared using a standard mixing method developed for work with premix material and salt solution in the ACTL grout laboratory. ${ }^{5}$ After mixing, each of the fresh saltstone slurries was poured into three 2 x 4 inch plastic cylinder molds and one sample cylinder (1 x 2 inch) for measuring hydraulic conductivity using the centrifuge. Batches 2 and 3 were also poured into a 2 liter plastic bottle (Table 2-1). This was done in order to provide different options for collecting the samples from the SPF process room as a contingency if collecting the grout in cylinders proved to be too difficult. ${ }^{3}$

Table 2-1. Samples matrix for transportation study.

\begin{tabular}{|l|c|l||}
\cline { 2 - 3 } \multicolumn{1}{c|}{} & $\begin{array}{c}\text { Time After Mixing } \\
\text { and Pouring, Before } \\
\text { Transporting }\end{array}$ & \multicolumn{1}{c||}{ Samples Transported } \\
\hline Batch 1 & 1 day & $\begin{array}{l}\text { Triplicate } 2 \times 4 \text { inch cylinders, one } 1 \text { x2 inch cylinder } \\
\text { for hydraulic conductivity }\end{array}$ \\
\hline Batch 2 & 1 hour & $\begin{array}{l}\text { Triplicate } 2 \text { x } 4 \text { inch cylinders, one } 1 \text { x2 inch cylinder } \\
\text { hydraulic conductivity, one 2-L bottle }\end{array}$ \\
\hline Batch 3 & 0 min & $\begin{array}{l}\text { Triplicate } 2 \times 4 \text { inch cylinders, one } 1 \text { x2 inch cylinder } \\
\text { hydraulic conductivity, one 2-L bottle }\end{array}$ \\
\hline \hline
\end{tabular}




\subsection{Transporting and Curing Samples}

After the samples were poured into their respective containers, the samples for Batch 3 (cylinder molds and 2 liter bottles) were immediately loaded into a truck, driven around, and returned to the laboratory. The samples in Batch 1 (cylinder molds only) and Batch 2 (cylinder molds and 2 liter bottles) were allowed to set for 1 day and 1 hour, respectively, prior to transportation. After being transported, the material from the 2 liter bottles for Batches 2 and 3 were each poured into three 2 $\mathrm{x} 4$ inch cylinder molds. Since curing temperature is not a factor for this specific testing, the samples were cured for 28 days in a humid environment (closed molds) at room temperature. The samples were capped and cured in a plastic bag with a wet cloth to maintain a humid environment.

\subsection{Fresh Properties}

All of the samples were analyzed for bleed water and set time within the first three days of curing. Bleed, or standing, water is determined as a function of sample volume. Set time is determined using the ASTM Vicat Needle method. ${ }^{6}$

\subsection{Cured Properties}

After the samples cured for 28 days, the cured properties of the samples were analyzed. The density $\left[\mathrm{g} / \mathrm{cm}^{3}\right.$ ] of each $2 \times 4$ inch cylinder was determined using helium pycnometry as well as ASTM C 642-06. ${ }^{7,8}$ Each 2 x 4 inch cylinder was sliced into six equal size disks (Figure 2-1) and the density of each disk was measured.

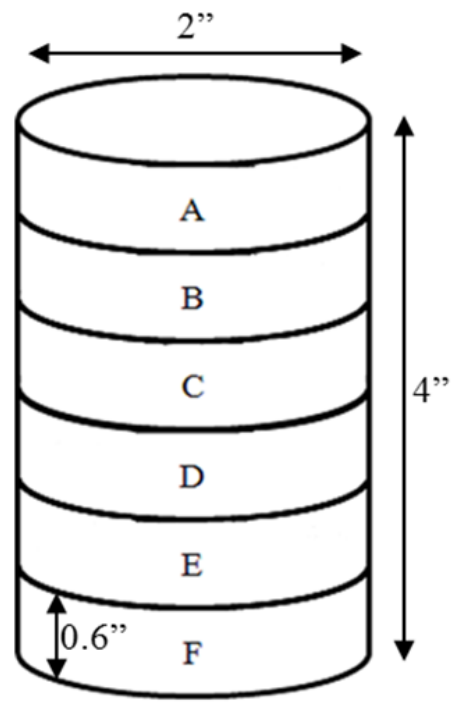

Figure 2-1. Sectioning of $2 \times 4$ inch samples for density measurements.

The ASTM method was followed with the exception of sample size. Section 4.1 of the ASTM procedure specifies a sample size of approximately 800 grams. Since each section from the $2 \times 4$ inch cylinder weighed approximately 50 grams, a reduced sample size was used. Using the calculations in the ASTM method, the bulk densities, apparent density, and volume of permeable pore space were calculated for each section of the 2 x 4 inch cylinders.

The saturated hydraulic conductivity [ $\mathrm{cm} / \mathrm{s}$ ] of each sample was measured using the centrifuge following ASTM D 6527-00. ${ }^{9}$ The samples were vacuum saturated prior to loading them into the centrifuge. ${ }^{10}$ The centrifuge was operated at $5000 \mathrm{rpm}$ and the permeant, water, was fed gravitationally to the sample which promotes and maintains saturation of the samples. The hydraulic conductivity was calculated from Darcy's law using the flow of the permeant liquid 
through the porous medium over time. ${ }^{9}$ Equation 2-1 shows Darcy's law rearranged for when the rotational speed is above $300 \mathrm{rpm}$.

$$
q=K\left(\rho \omega^{2} r\right)
$$

Where: $\mathrm{K}=$ hydraulic conductivity [cm/s]

$\mathrm{r}=$ distance from the axis of rotation $[\mathrm{cm}]$

$\rho=$ water density $\left[\mathrm{g} / \mathrm{cm}^{3}\right]$

$\omega=$ rotational speed [radians/s]

$\mathrm{q}=$ water flux density $[\mathrm{cm} / \mathrm{s}]$

\subsection{Results and Discussion}

\subsection{Fresh Properties}

The fresh properties of the grout mixes were measured to baseline the simulated saltstone slurries to other saltstone slurries formulated in the laboratory. All of the mixes were tested for set and bleed one and three days after they were made (Table 3-1). The acceptability limit of set and bleed are the slurry is set within three days with less than three volume percent bleed. ${ }^{11}$ The values for bleed water in Table 3-1 are averages from triplicate samples. The samples in batches 2a and $3 \mathrm{a}$ are $2 \times 4$ inch cylinders that were poured from the $2 \mathrm{~L}$ bottle after it was transported. It should be noted that the grout slurry in the $2 \mathrm{~L}$ bottles had gelled during transportation and had to be remixed manually in order to pour the material into the 2 x 4 inch cylinders. Since the slurry was so thick, it was not possible to make a sample for hydraulic conductivity.

Table 3-1. Fresh properties of saltstone transportation samples

\begin{tabular}{|c|c|c|c||}
\hline Sample & Set [mm] & Bleed [vol \%] Day 1 & Bleed [vol \%] Day 3 \\
\hline \hline Batch 1 & $<1$ day & 0 & 0 \\
\hline Batch 2 & $<1$ day & 0 & 0 \\
\hline Batch 3 & $<1$ day & 0 & 0 \\
\hline Batch 2a & nm & 2.35 & 2.03 \\
\hline Batch 3a & nm & 1.32 & 0.82 \\
\hline
\end{tabular}

nm - not measured

\subsection{Cured Properties}

After curing for 28 days, the density and hydraulic conductivity of the samples were measured. The samples from Batches 2a and 3a were not measured for density since it was already determined that the $2 \mathrm{~L}$ collection method was not viable. The pycnometer was also used to verify the bulk density of the samples (Table 3-2). The ASTM C642-06 method was used to measure the bulk density and volume of permeable pore spaces in each section of the $2 \times 4$ inch cylinder using Equations 2-2 to 2-6 (Table 3-3). For this study, the "bulk density after immersion" will be used as the sample density as measured by the ASTM method. It should be noted that the volume of permeable pore spaces and the bulk density have an inverse relationship (Table 3-3). As shown in Table 3-2, Table 3-3 and Figure 3-1, section F of all three batches has the highest density and lowest pore volume of all the cylinder sections which is indicative of some settling occurring in all the samples. There is no clear density trend for sections A - E of the sample cylinders. As shown in Figure 3-1, the measured density for the pcynometry samples is slightly higher than the densities measured by the ASTM C642-06 method. This is due to the helium gas being a smaller 
molecule size than water and being able to enter more pore spaces than water in the ASTM method. The two different methods were used in an attempt to get resolution of a density gradient, if any, existing in the cylinders as a result of transportation.

Table 3-2. Density $\left[\mathrm{g} / \mathrm{cm}^{3}\right]$ of saltstone transportation samples measured by pycnometry.

\begin{tabular}{|c|c|c|c||}
\cline { 2 - 4 } \multicolumn{1}{c|}{} & Batch 1 & Batch 2 & Batch 3 \\
\hline \hline A & 1.71 & 1.70 & 1.70 \\
\hline B & 1.71 & 1.70 & 1.71 \\
\hline C & 1.71 & 1.70 & 1.70 \\
\hline D & 1.70 & 1.70 & 1.71 \\
\hline E & 1.71 & 1.71 & 1.71 \\
\hline F & 1.72 & 1.71 & 1.73 \\
\hline
\end{tabular}

Table 3-3. Measured densities and pore volumes for saltstone transportation samples according to ASTM C642-06.

\begin{tabular}{|c|c|c|c|c|c|}
\hline Sample ID & $\begin{array}{c}\text { Bulk } \\
\text { Density, } \\
\text { dry }\left[\mathrm{g} / \mathrm{cm}^{3}\right]\end{array}$ & $\begin{array}{c}\text { Bulk Density } \\
\text { after } \\
\text { immersion } \\
{\left[\mathrm{g} / \mathrm{cm}^{3}\right]}\end{array}$ & $\begin{array}{c}\text { Bulk Density } \\
\text { after immersion } \\
\text { and boiling } \\
{\left[\mathrm{g} / \mathrm{cm}^{3}\right]}\end{array}$ & $\begin{array}{c}\text { Apparent } \\
\text { Density } \\
{\left[\mathrm{g} / \mathrm{cm}^{3}\right]}\end{array}$ & $\begin{array}{c}\text { Volume of } \\
\text { permeable pore } \\
\text { spaces } \\
\text { [\%] }\end{array}$ \\
\hline Batch $1-\mathrm{A}$ & 1.103 & 1.686 & 1.669 & 2.544 & 56.642 \\
\hline Batch $1-$ B & 1.093 & 1.699 & 1.662 & 2.534 & 56.847 \\
\hline Batch $1-\mathrm{C}$ & 1.073 & 1.692 & 1.652 & 2.552 & 57.937 \\
\hline Batch $1-\mathrm{D}$ & 1.086 & 1.696 & 1.661 & 2.555 & 57.499 \\
\hline Batch $1-\mathrm{E}$ & 1.131 & 1.691 & 1.687 & 2.544 & 55.520 \\
\hline Batch $1-\mathrm{F}$ & 1.158 & 1.710 & 1.704 & 2.550 & 54.594 \\
\hline Batch $2-\mathrm{A}$ & 1.125 & 1.683 & 1.679 & 2.520 & 55.352 \\
\hline Batch 2-B & 1.141 & 1.693 & 1.688 & 2.520 & 54.712 \\
\hline Batch $2-\mathrm{C}$ & 1.093 & 1.668 & 1.658 & 2.514 & 56.545 \\
\hline Batch $2-\mathrm{D}$ & 1.125 & 1.687 & 1.679 & 2.519 & 55.320 \\
\hline Batch $2-E$ & 1.120 & 1.681 & 1.674 & 2.510 & 55.380 \\
\hline Batch 2-F & 1.174 & 1.725 & 1.720 & 2.585 & 54.568 \\
\hline Batch $3-\mathrm{A}$ & 1.125 & 1.700 & 1.683 & 2.545 & 55.784 \\
\hline Batch $3-B$ & 1.135 & 1.696 & 1.689 & 2.543 & 55.390 \\
\hline Batch $3-\mathrm{C}$ & 1.129 & 1.692 & 1.684 & 2.541 & 55.581 \\
\hline Batch $3-\mathrm{D}$ & 1.136 & 1.695 & 1.686 & 2.525 & 55.009 \\
\hline Batch $3-E$ & 1.140 & 1.698 & 1.688 & 2.522 & 54.800 \\
\hline Batch $3-F$ & 1.153 & 1.713 & 1.700 & 2.544 & 54.685 \\
\hline
\end{tabular}




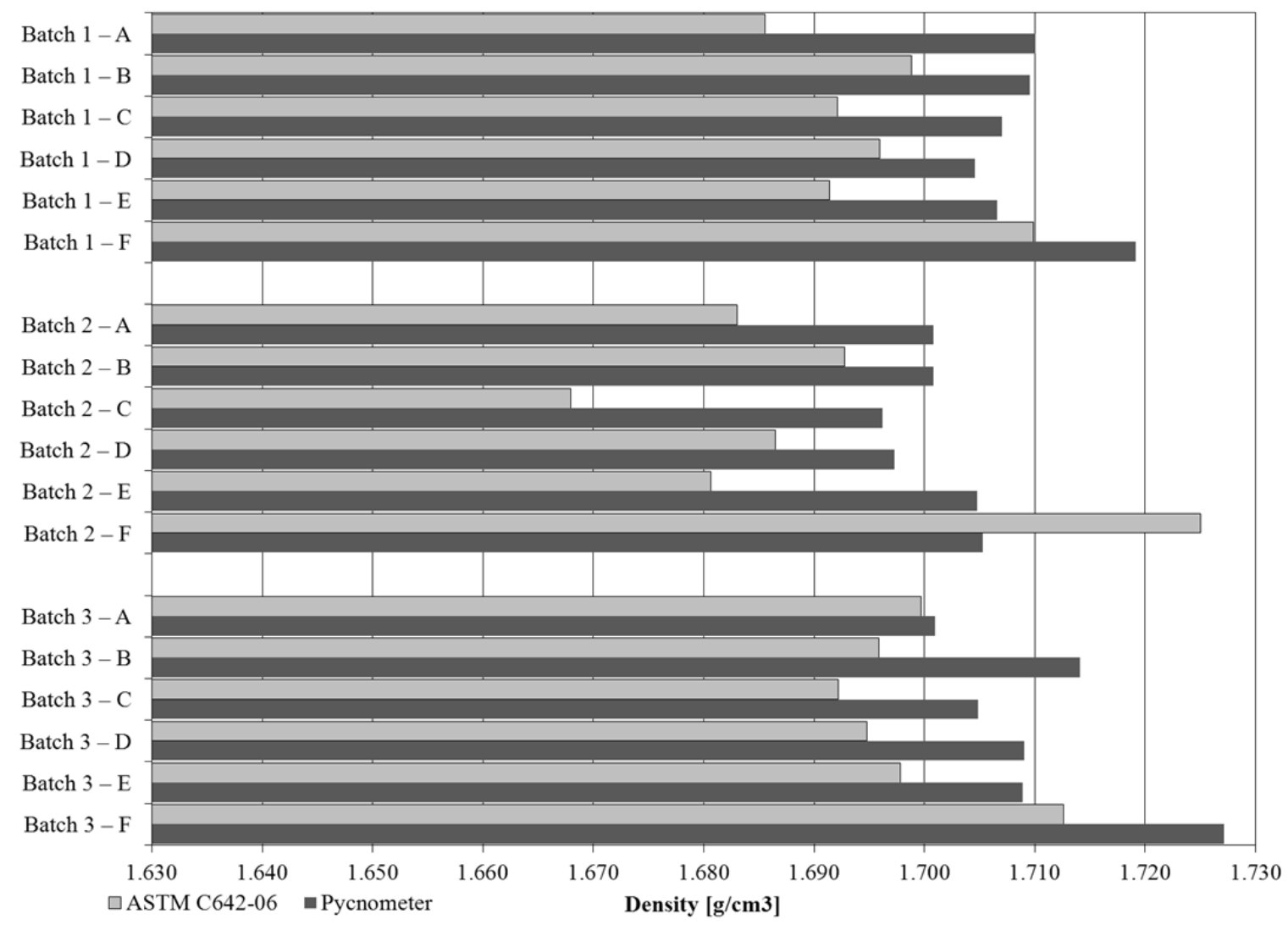

Figure 3-1. Measured densities for all samples by Pycnometry and ASTM C642-06.

The average of triplicate hydraulic conductivity measurements on the hydraulic conductivity sample from each batch is listed in Table 3-4 and provided graphically in Figure 3-2. Batch 3, which was transported immediately after mixing, had the highest hydraulic conductivity of all samples tested. Conversely, Batch 2, which was allowed to sit for an hour before being transported, had the lowest hydraulic conductivity. However, all three samples had hydraulic conductivities that fell within an acceptable range.

Table 3-4. Hydraulic Conductivities for saltstone transportation samples

\begin{tabular}{|c|c|c||}
\hline Sample & $\mathbf{K}_{\text {sat }}[\mathbf{c m} / \mathbf{s}]$ & Std. Dev. \\
\hline Batch 1 & $1.1 \mathrm{E}-09$ & $2.8 \mathrm{E}-10$ \\
\hline Batch 2 & $1.8 \mathrm{E}-10$ & $1.2 \mathrm{E}-10$ \\
\hline Batch 3 & $4.2 \mathrm{E}-09$ & $1.6 \mathrm{E}-9$ \\
\hline
\end{tabular}


SRNL-STI-2013-00261

Revision 0

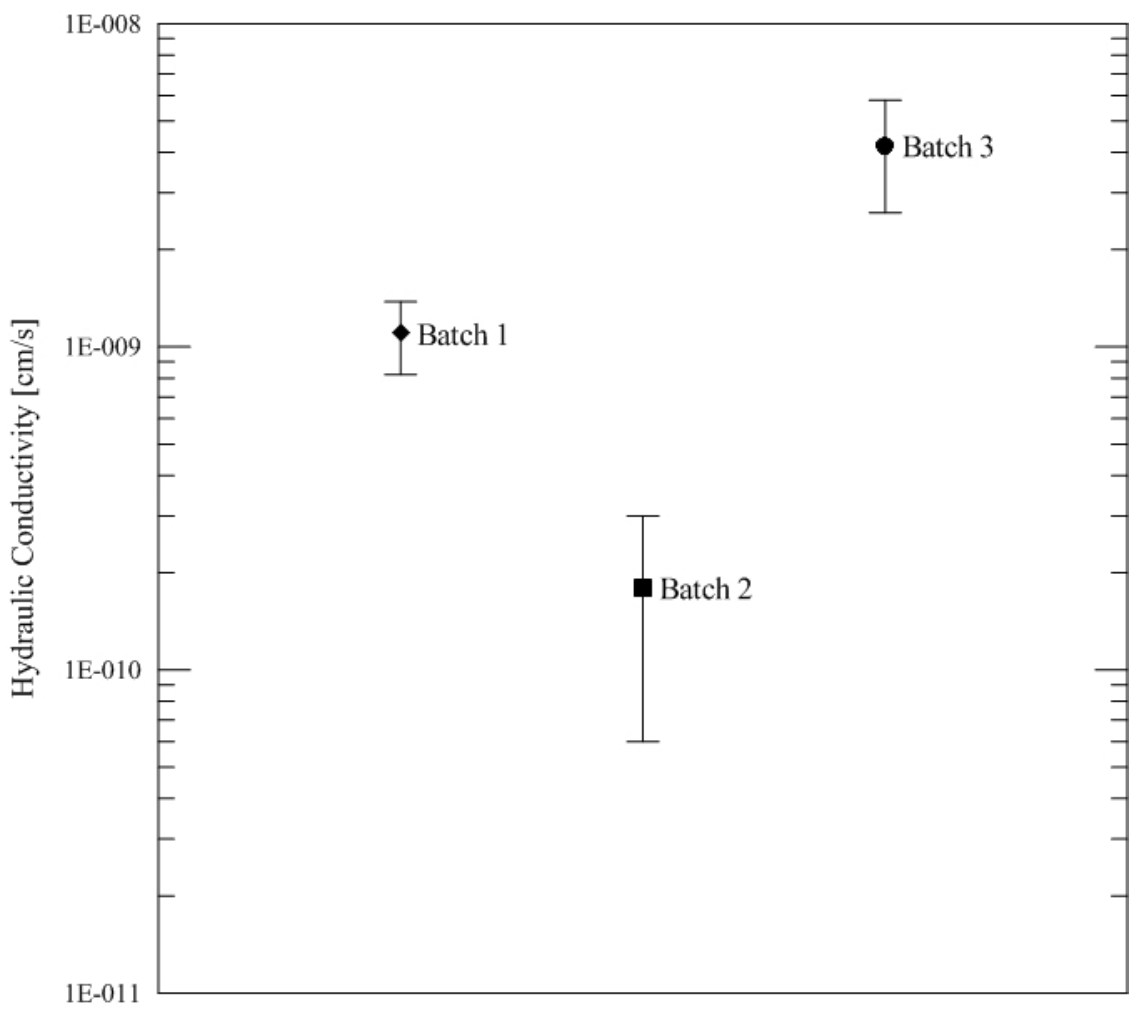

Figure 3-2. Hydraulic conductivity of saltstone transportation samples

\subsection{Conclusions}

SRR tasked SRNL with performing testing to assess the potential consolidation of grout associated with transportation from the SPF to SRNL. Three separate batches of simulated saltstone were mixed in the ACTL grout laboratory and allowed to sit for various amounts of time before they were driven on site roads for approximately 15 miles to simulate the distance from the SPF to SRNL. Although the volume of bleed produced by all the batches met the acceptability limits of less than 3 volume percent, it is not recommended to collect the material in $2 \mathrm{~L}$ bottles for transportation to SRNL since the gelling that occurs during transportation makes subsampling very difficult. All of the samples were set within one day after mixing. The results of this testing showed there was no clear distinction between the densities of the cylinder sections for any of the transportation scenarios tested, indicating that no significant consolidation of the simulated saltstone occurred as a result of transportation. The bottom section of each cylinder was the densest for each transportation scenario, which indicates some settling in all the samples.

Triplicate hydraulic conductivity measurements on each transportation resulted in Batch 3, which was transported immediately after mixing, had the highest hydraulic conductivity of all samples tested. Conversely, Batch 2, which was allowed to sit for an hour before being transported, had the lowest hydraulic conductivity. However, the hydraulic conductivities of all three samples fell within an acceptable range. Based on the cured property analysis of the three samples, there is no clear conclusion about transporting the samples before they are set; however, experience with saltstone grout indicates the samples should sit and develop some structure before being transported to SRNL for curing. 


\subsection{References}

1. Simner, S.P., "Saltstone Sampling and Analyses Plan," Savannah River Remediation, SRR-SPT-2012-00049, Revision 1, May 2013 (in draft).

2. Huff, T., "SRNL Support for Phase I of Saltstone Sampling and Analysis," Savannah River Remediation, HLE-TTR-2012-020, Revision 0, December 18, 2012.

3. Reigel, M.M., "Task Technical and Quality Assurance Plan for Determining the Effect of Transporting Saltstone Samples Prior to Set," Savannah River National Laboratory, SRNL-RP-2013-00036, February 6, 2013.

4. $\quad$ Reigel, M.M. and Bibler, N.E., "Tables Containing Results for the First Quarter 2011 Tank 50 WAC Sample: Chemical and Radionuclide Contaminant Results," Savannah River National Laboratory, Aiken, SC, SRNL-L3100-2011-00011 Rev. 1, March 28, 2011.

5. Cozzi, A.D., "Task Technical and Quality Assurance Plan for Hanford Low Activity Waste Cast Stone Screening Test Matrix," Savannah River National Laboratory, Aiken, SC, SRNL-RP-2012-00816, Revision 0, 2012.

6. "Standard Test Methods for Time of Setting of Hydraulic Cement by Vicat Needle," ASTM International, ASTM C 191 - 08.

7. "Standard Test Method for Density, Absorption, and Voids in Hardened Concrete," ASTM International, ASTM C 642 - 06.

8. Cozzi, A.D. and Pickenheim, B.R., "Impact of Pouring into Standing Water," Savannah River National Laboratory, September 2012.

9. "Standard Test Method for Determining Unsaturated and Saturated Hydraulic Conductivity in Porous Media by Steady State Centrifugation," ASTM International, ASTM D 6527 - 00 (2008).

10. Harbour, J.R. and Williams, M.F., "Impact of Curing Temperature on the Saturated Liquid Permeability of Saltstone," Savannah River National Laboratory, SRNL-STI2010-00745, Revision 0, February 2011.

11. Langton, C.A. and Burket, P.R. and Hansen, E.K. and Herman, D.T., et al., "Tank 50 Batch 0 Saltstone Formulation Testing," Savannah River National Laboratory, WSRCTR-2005-00498, January 30, 2006. 


\section{Distribution:}

$\begin{array}{ll}\text { T. B. Brown } & 773-A \\ \text { G. B. Clendenen } & 704-14 \mathrm{E} \\ \text { D. R. Click } & 999-\mathrm{W} \\ \text { J. S. Contardi } & 704-\mathrm{S} \\ \text { A. D. Cozzi } & 999-\mathrm{W} \\ \text { S. D. Fink } & 773-\mathrm{A} \\ \text { K. M. Fox } & 999-\mathrm{W} \\ \text { C. C. Herman } & 773-\mathrm{A} \\ \text { E. N. Hoffman } & 999-\mathrm{W} \\ \text { T. H. Huff } & 707-13 \mathrm{E} \\ \text { V. Jain } & 704-\mathrm{Z} \\ \text { C. A. Langton } & 773-\mathrm{A} \\ \text { S. L. Marra } & 773-\mathrm{A} \\ \text { W. D. Mathison } & 210-\mathrm{Z} \\ \text { F. M. Pennebaker } & 773-42 \mathrm{~A} \\ \text { K. H. Rosenberger } & 705-1 \mathrm{C} \\ \text { L. C. Scott } & 241-169 \mathrm{H} \\ \text { S. C. Shah } & 704-14 \mathrm{Z} \\ \text { S. P. Simner } & 249-8 \mathrm{H} \\ \text { F. M. Smith } & 705-1 \mathrm{C} \\ \text { S. A. Smith } & 705-1 \mathrm{C} \\ \text { A. V. Staub } & 704-27 \mathrm{~S} \\ \text { C. R. Whitehurst } & 707-13 \mathrm{E}\end{array}$

